\title{
Development of rail infrastructure and its impact on urbanization in the Randstad, the Netherlands
}

\author{
Dena Kasraian \\ Delft University of Technology \\ D.Kasraianmoghaddam@tudelft.nl
}

\author{
Kees Maat \\ Delft University of Technology \\ C.Maat@tudelft.nl
}

\section{Bert van Wee \\ Delft University of Technology \\ G.P.vanWee@tudelft.nl}

\begin{abstract}
Long-term, large-scale empirical studies on the simultaneous development of transport infrastructure and the built environment are scarce. This paper provides a long-term study of the development of the railway network and its impact on the built-up area-and vice versa-using the case study of the Randstad in the Netherlands between 1850 and 2010. The analysis is both qualitative and quantitative. We describe the shares of the built-up area in concentric buffers of 1-kilometer intervals from railway stations and estimate binomial logit models to predict the likelihood of new stations being built based on the amount of the preceding and subsequent built-up area and the likelihood that a new station might have encouraged further growth. Results show that during the early days stations followed existing urbanization patterns. But as time went by, new stations were more likely to be located in undeveloped areas and less likely to be located within the established built-up areas, which were already serviced by existing stations. Moreover, they prompted further growth, increasing the likelihood of more urbanization in their vicinity.
\end{abstract}

\section{Article history:}

Received: November 30, 2013

Received in revised form: August 31, 2014

Accepted: December 16, 2014

Available online: September 15, 2015

\section{Introduction}

A key question in urban studies is how urban areas expand. Understanding the determinants of urban growth and the consequences of their interaction is critical information for many people, from economic geographers to spatial planners and policymakers who aim to guide and channel future urban development. Many have argued the structuring role played by transport infrastructure in shaping the cities over time (e.g., Hoyt 1939; Mumford 1961; Rodrigue, Comtois, and Slack 2009). Furthermore, it has been observed that transport infrastructure, urbanization (more generally referred to as land use), and travel behavior are all interrelated. Infrastructure improvements increase accessibility, making land more valuable for further development; conversely, land development creates travel demand, and con-

Copyright 2015 Dena Kasraian, Kees Maat \& Bert van Wee

http://dx.doi.org/10.5198/jtlu.2015.665

ISSN: 1938-7849 | Licensed under the Creative Commons Attribution - Noncommercial License 3.0

The Journal of Transport and Land Use is the official journal of the World Society for Transport and Land Use (WSTLUR) and is published and sponsored by the University of Minnesota Center for Transportation Studies. This paper is also published with sponsorship from WSTLUR and the Institutes of Transportation Studies at the University of California, Davis, and the University of California, Berkeley. 
sequently induces the need for infrastructure improvements (Giuliano 2004).

The interrelationships between transport infrastructure development, land use, and travel behavior have been investigated from a variety of perspectives. Many studies focus on the impact of land use, as the spatial embodiment of human activities, on travel behavior (for an overview, see Ewing and Cervero 2010), primarily as cross-sectional studies. Another part of the literature is dedicated to the relationship between transport infrastructure and regional economic development. Here, from the viewpoint of urban economics, research focuses on investigating the impact of mainly large-scale transport infrastructure such as highways or high-speed rails on economic changes at the regional level, usually in the form of before-after analyses involving aggregated data (Rietveld and Bruinsma 1998; Banister and Berechman 2001). In addition, some studies have looked at how infrastructure affects land or property values (for an overview, see Huang 1994).

A limited number of studies have used long-term empirical data to analyze the relationship between the development of infrastructure network and the built environment, the latter also referred to as land use. This relationship can only be studied over a long time period because both infrastructure development and land use development are lengthy processes, and moreover, the influence of one on the other is likely to take even more time to become evident (Wegener, Gnad, and Vannahme 1986). One significant reason for the lack of long-term studies into this interaction is the lack of consistent data over a longer period (Badoe and Miller 2000). The few studies that have managed to overcome this difficulty have measured changes in accessibility as a result of changes in the infrastructure network and its consequence for accessible population or population density, usually within different degrees of proximity to the infrastructure (Atack et al. 2010; Axhausen, Froelich, and Tschopp 2011; Koopmans, Rietveld, and Huijg 2012; Duranton and Turner 2012). Looking at the demographic details, some researchers have distinguished between working and residential populations and investigated their redistribution over time in relation to access to transport infrastructure (Giuliano et al. 2012; Herranz-Loncán 2007; Bollinger and Ihlanfeldt 1997). All these studies investigate the association between infrastructure development and population density change. While change in population density is a reasonable proxy for land-use change over time, it may well overlook changes in land consumption, i.e., the expansion of urban land coverage. In other words, changes to land developed for dwellings and other urban functions are not always captured by population figures. For instance, the population (density) of a municipality may remain steady while the urban land coverage may rise because of a decrease in the number of persons per household.

There is now an increasing number of studies that aim to explain the interaction between infrastructure and urban land coverage itself. These studies generally make use of digitized aerial photos. However, they usually cover a period of at most a couple of decades during the second half of the $20^{\text {th }}$ century and are rarely conducted at urban scales larger than city regions. For instance, Stanilov (2003) and Demirel et al. (2008) investigated the impact of road transport on land-use distribution pattern and the growth of urban areas within the city regions of Seattle and Istanbul, respectively. To our knowledge, no studies have investigated the relationship between the railway network and urban land use during a period of over a century at a regional level.

By "urban land" we mean the physical space that is used for urban functions, including real estate for housing, services, and companies, as well as infrastructure and parks. This is what we generally refer to as the built-up area (BUA). The lack of studies in this field is remarkable, because the most basic process of urbanization is the conversion of unbuilt land into built-up areas. When we discuss the issue of suburbanization (Dieleman, Dijst, and Spit 1999) or urban sprawl (Anas, Arnott, and Small 1998), for example, we are basically referring to a physical change in the landscape.

This paper deals with the shortcomings of the existing literature described above by providing a 
regional-level, long-term analysis of the impact of transport infrastructure (in this case the railway network) on urbanization (measured as the amount of built-up area) and vice versa. The case study area is the Randstad, the economic and population core of the Netherlands, which we analyze over the period between 1850 (after the introduction of the railways) and 2010 .

Regarding transport infrastructure, we limit ourselves to the railway network. Railway lines have played a key role in the urbanization processes in many parts of the world since the mid-19 ${ }^{\text {th }}$ century. However, since the mid- $20^{\text {th }}$ century, the role of the rail network has been replaced to a large extent by the use of the car and the expanding road and motorway network. Unlike in the United States, in Europe the train and other public transport modes, continued to play a significant role in everyday travel. Moreover, policymakers have always considered public transport as an important means of tackling road traffic congestion (Banister 2005). We aim to explain the influence of railway stations on the growth of BUA in the Randstad area. We describe urbanization by using buffers with a 5-kilometer radius around the railway stations as units of analysis in our models. Our main focus is on the evolution of the railway network and the development of the BUA with regard to the buffers of railway stations and across the entire study area.

Our research questions are:

- How has the railway network evolved in the Randstad, from the time of its introduction to the present day?

- How has the process of urbanization, measured as the amount of built-up area (BUA), taken place at varying degrees of proximity to the railway stations during this period?

- Does the opening of new railway stations encourage the development of BUA in their vicinity, and vice versa?

We answer these questions by using a hybrid method that combines qualitative descriptions with quantitative analysis. To answer our first question, we generate descriptive graphs of the evolution of the railway network, including both the number of stations and the length of lines at annual intervals from the beginning of the network to the present day, as well as maps showing the growth of the network at decennial intervals. To this quantitative picture, we add qualitative explanations from the (recent) literature. To answer our second question, we use simple quantitative measures to describe the process of urbanization by relating the built-up area to the degree of proximity to the railway stations. And to answer our third question, we use binomial logit models, which estimate the likelihood of a new station being opened as a function of the amount of BUA in its 5-kilometer circular buffer during the periods immediately before and after.

The rest of this paper is structured as follows. In Section 2, we describe the study area and the data. To address our first question, Section 3 describes the development of the railway network using graphs and maps derived from the data and supplemented with historical literature. Section 4 focuses on the second and third research questions and encompasses the analyses of the development of built-up area in relation to the railway stations. In the final section, we discuss our conclusions.

\section{$2 \quad$ Data and method}

For the empirical study of the evolution of the railway network and the built-up area (BUA), a unique database was constructed, using GIS, bringing together various sources for both for the period under study. There are different demarcations for the Randstad area and this variety is reflected in the studies (e.g., Laan 1998; Clark and Kuijpers-Linde 1994; van Eck and Snellen 2006). However, to the best of our knowledge, all definitions include the four main cities of Amsterdam, Utrecht, Rotterdam and The Hague. Our chosen study area is the common denominator of all data sources available to us (Figure 1a). There may be minor differences with other Randstad boundaries in the north and east. This area remains 
the same until 1968 after which it grows by 8 percent due to the new Flevoland province, which is made up of land reclaimed from the IJsselmeer. Within this study area, analyses were performed on stations belonging to a smaller region, indicated in dark grey in Figure 1b, so that changes in their surroundings would still be included in the study area.
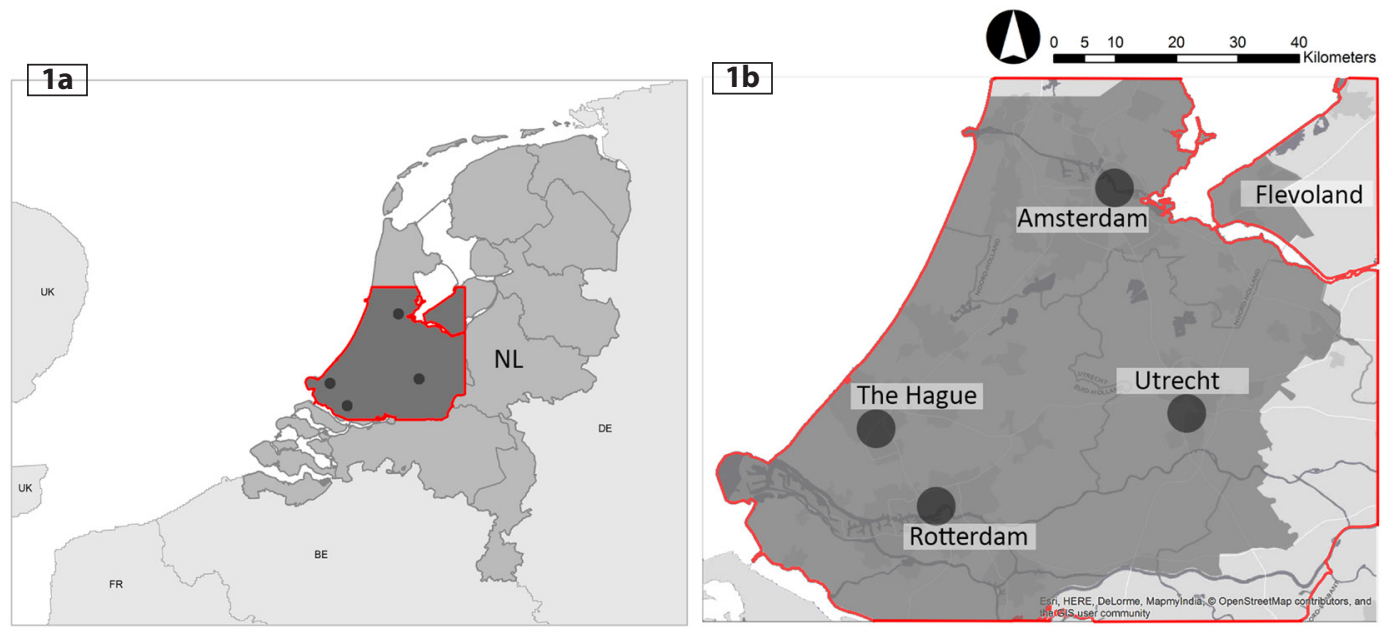

Figure 1: a) Study area (the Randstad) in the Netherlands, b) train stations and their surroundings in the dark grey area were analyzed

Gathering and building up a consistent database of the development of BUA was one of the main challenges of our research. Not only were the data sources and types different, but the measurement and categorization of BUA were also not always consistent. We compared various data sources and their classification of BUA (i.e., buildings and paved surfaces plus transport infrastructure), and we chose the following three data sources and the most comparable categories measuring BUA between them (See Table 1): first, digitized vector files of the built-up area produced by the Mapping Randstad Holland group of the Delft University of Technology (Engel and Claessens 2005); second, the Historical Land Use Maps of the Netherlands (HGN) from the geo-information center at the University of Wageningen, Alterra (Kramer and van Dorland 2009); and third the "adjusted version" of the Land Use Dataset (Mutatiereeks Bodemgebruik 1996-2010), created by Statistics Netherlands (CBS) and The Netherlands' Cadastre, Land Registry and Mapping Agency (Kadaster). This database was specifically created to track detailed and consistent changes in land use from 1996 to 2010.

By selecting comparable data sources and similar categories to represent the BUA, we have attempted to create a consistent long-term database. However, there is one caveat concerning the comparability of the BUA before and after 1990. Here, we see a trend break as a result of the shift from the HGN database to the CBS Mutatiereeks. The reason is that the former is based on existing land cover, while the latter is defined by land-use type. This may be problematic where a designated land use has not yet developed, for instance, some undeveloped office areas may still be classified as "fields" in HGN, while the CBS Mutatiereeks includes them as built-up areas based on their land use (Kramer and van Dorland 2009). This results in a higher representation of BUA for the last two time points. However, we believe this will not have a substantial effect on our outcomes since it would be spread equally across the study area. 
Table 1: Data sources for built-up area and their formats per time point

\begin{tabular}{lll}
\hline Year & Source & Type \\
\hline 1850 & OverHolland, Delft University of Technology & Vector \\
1910 & OverHolland, Delft University of Technology & Vector \\
1940 & OverHolland, Delft University of Technology & Vector \\
1960 & HGN, Alterra, Wageningen University & Raster (cell size: $25^{*} 25$ m) \\
1970 & HGN, Alterra, Wageningen University & Raster (cell size: $25^{*} 25$ m) \\
1980 & HGN, Alterra, Wageningen University & Raster (cell size: $25^{*} 25$ m) \\
1990 & HGN, Alterra, Wageningen University & Raster (cell size: $25^{*} 25$ m) \\
2000 & Mutatiereeks Bodemgebruik 1996-2010 (year 2000), CBS Vector \\
2010 & Mutatiereeks Bodemgebruik 1996-2010 (year 2010), CBS Vector \\
\hline
\end{tabular}

As for the development of the railway lines and stations, we digitized the entire network with regard to passenger transport at annual intervals. This provided us with a detailed and accurate insight into the development of the railway network during our study period. We started with the state-of-the-art National Railways dataset (Nationaal Georegister 2011). We then moved back in time toward 1839 removing (and sometimes adding) railway lines and stations on a year-by-year basis. The change of location of a specific station on its railway line was only mapped if it was moved more than 500 meters from its original position. Sluiter (2002) was consulted for the start and end dates of passenger services. We also used open source databases, namely the website stationsweb.nl and the Google OpenStreetMap (OSM), for the coordinates of stations that were closed down. Where no coordinates were available, these stations were located using address details or the distance to their neighboring stations (linear referencing) and with regard to the geographical context.

We apply a hybrid method combining qualitative descriptions with quantitative analyses. The result of the detailed mapping of the development of the railway network is presented in Section 3.1 as descriptive graphs (Figure $2 \mathrm{a}-\mathrm{e}$ ) accompanied by historical descriptions from the literature (Section 3.2). In Section 4.1, we analyze the process of urbanization by relating BUA to station buffers and applying some simple spatial analyses in ArcGIS 10. Here we generate a 1-kilometer circular buffer (0-1 kilometer) and four non-overlapping ring buffers at 1-kilometer intervals (1-2 kilometers, 2-3 kilometers, 3-4 kilometers, 4-5 kilometers) around the stations that existed at any of the nine time points. These buffers are then intersected with the BUA at each time point, and the amount of BUA (in square kilometers) within them is compared to each other and the rest of the study area. The results are presented in Figures 5 and 6. In Section 4.2, we estimate seven binomial logit models. Here we use the amount of BUA in the 5-kilometer circular buffers (obtained by merging all previous buffers) at different time points to predict the effect of BUA on the probability of new stations opening and vice versa.

\section{Development of the railway network}

\subsection{Overview}

The development of the rail network in the Randstad is a history of growth, decline, and revival. This section provides an overview of the development of the railway network, including the total length of railway lines and station numbers. Figure $2 \mathrm{a}$ shows the number of railway stations in the study area, starting with a steep rise between 1839 and 1920, followed by a reduction of more than half between the 1920s and 1950s, and a more gradual revival since then. While Figure 2a shows the cumulative situation, Figure $2 \mathrm{~b}$ shows the numbers of stations opening and closing in each decade. Figure $2 \mathrm{c}$ depicts the changes in the total length of railway lines in the region. During the period of growth leading up to 1920, the growth of the network length took place earlier than the growth in the number of stations, 
because railway lines are needed before railway stations can be developed. After a period of stabilization, some lines were closed; however, the reduction of the network length occurred later than the reduction in the number of stations, suggesting that the reduction of stations mainly involved smaller stops on remaining lines. Figure $2 \mathrm{~d}$ shows the length of lines added and closed in each decade.

Not surprisingly, the development of railway lines and stations both follow the same broad trend: growth to a peak by 1920 , decline between the 1930s and 1950s, and a period of stabilization around the 1960s before redevelopment, although at a slower pace, from the 1970s to the present day. A more detailed comparison nevertheless reveals that the number of stations has been rather volatile and experienced more variation than the total network length, probably because it is easier to establish, close down or move a station than to build a new railway line. This results in rapidly changing station densities (ratio of stations to lines) over time (see Figure 2e).
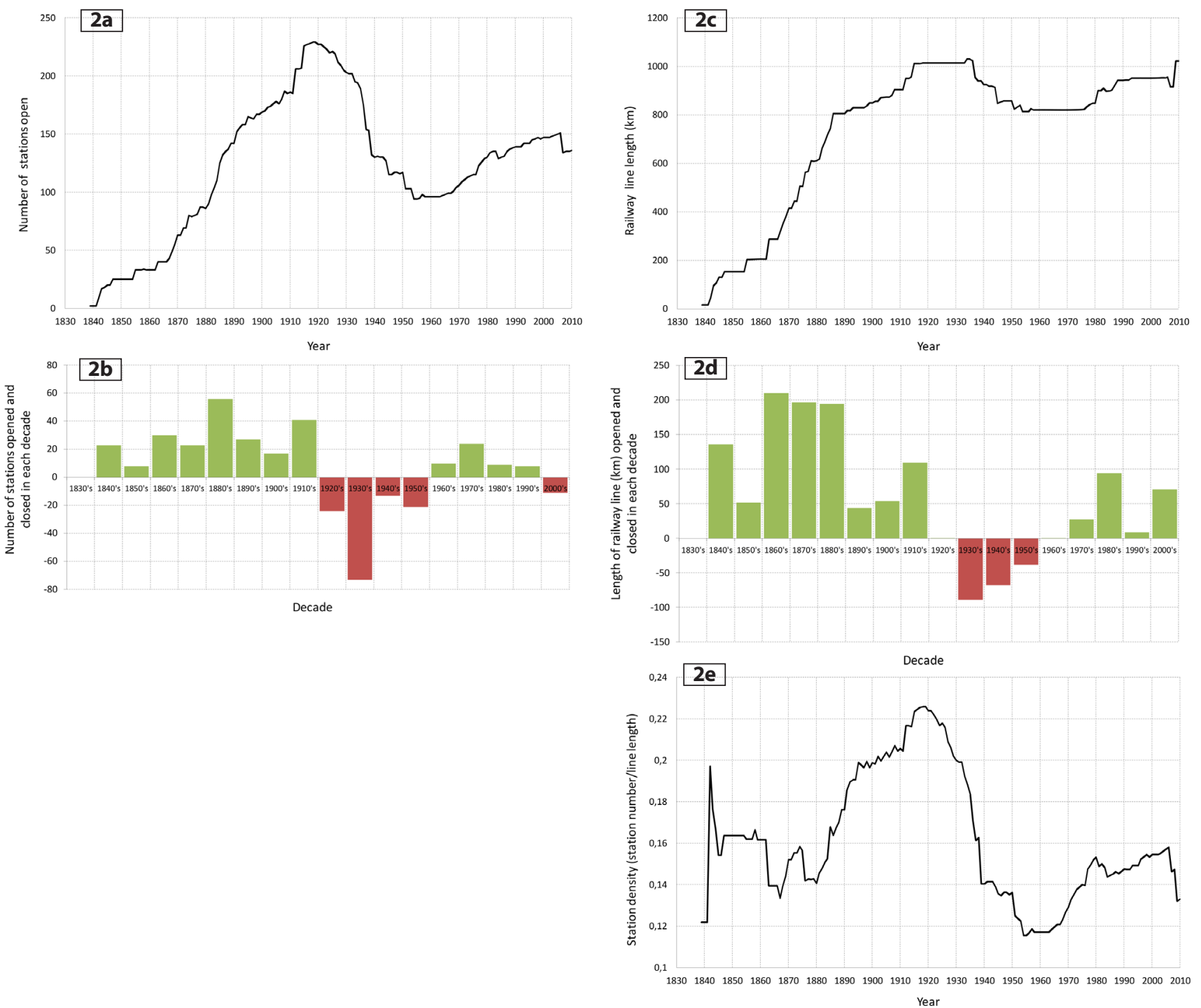

Figure 2: a) Number of stations open, b) number of stations opened and closed in each decade, c) railway line length (kilometers), d) length of railway line (kilometers) opened and closed in each decade, e) station density (station number/line length) Source: Authors 


\subsection{History of railway network development}

The development of the railway infrastructure is divided into four periods corresponding with our data points and coinciding with significant phases in railway development: 1850-1910, 1910-40, 1940-80, and 1980-2010. We describe the development of the railway network in the context of each era and add some words concerning the development of the urban area. Figure 3 depicts the development of the network over 18 decades.

Pre-1850, the advent of railways. The Dutch forerunner of the train was the trekschuit, a barge towed by horses along the canals. In 1839, the first Dutch railway was built between Amsterdam and Haarlem. The first railway lines were built along the existing canals and the competition between the two went on until the end of $19^{\text {th }}$ century when the barges finally conceded (van der Knaap 1978). From the outset, the rail network was not only market driven, but highly influenced by government policies. In the $19^{\text {th }}$ century, the government was planning to use the rail network to reinforce the position of Amsterdam and Rotterdam as important ports and centers of international transit (de Jong 1992). During that time, the urban structure consisted of many small towns, a small number of medium-sized ones and a few large ones (Deurloo and Hoekveld 1980). According to Dijksterhuis (1984), the railway network was not only designed to connect those cities, but also to connect the seaports with industrial hinterlands, and the Netherlands with its neighboring countries. See the early backbone structure of the railway network in Figure 3.

The railway boom: 1850-1910. The industrial revolution came rather late to the Netherlands, between 1850 and 1890 , resulting in demographic and economic growth in the second half of the $19^{\text {th }}$ century, accompanied by large-scale migration to the cities. The relatively late and limited process of industrialization in the Netherlands, competition from barges and unfavorable soil conditions were the main reasons behind the late development of the railway network in comparison to neighboring countries such as Belgium (Schmal 2003; Dijksterhuis 1989).

Late growth notwithstanding, this period, especially from 1860 to 1890 , is seen as the railway boom, in which the existing railway lines developed into an integrated transport network. The first Dutch railway lines did not include freight transportation but were constructed to meet the demand for passenger transport. Figure 3 shows the rapid development of the network in the second half of the $19^{\text {th }}$ century, resulting in a railway network that does not differ much from the current network. In the mid-1870s, the government allowed the removal of city fortifications, which resulted in urban growth beyond city walls, allowing Dutch cities to expand for the first time since the $17^{\text {th }}$ century in the decades that followed (1870-1920) and providing opportunities for new railways (Cavallo 2007).

To begin with, the railway lines connected the main population cores, but after 1870, there was more demand for connections to less populated regions and smaller cities and villages. Moreover, secondary stations were built on existing lines, which later supported the development of suburban areas (Cavallo 2007). During this period, the length of the railway network and levels of accessibility grew tremendously. Although the network continued to expand over the decades to come, the pace of growth slowed considerably (Koopmans, Rietveld, and Huijg 2012).

The location of railway lines for passenger transport parallel to canals and their role in connecting the existing settlements around transport connections led to a reinforcement of the existing urban structure (Dijksterhuis 1984). The network also connected and integrated large peripheral cities in the north and south of the country with the concentrated and more developed cities in what we now call the Randstad. The urban population increased along with improvements in accessibility. Suburbanization, however, was in its infancy during this period. The gradual construction and expansion of railway routes was a major stimulus in the trend toward further suburbanization.

Railways and early suburbanization: 1910-1940. Economic growth picked up considerably at 
the beginning of the $20^{\text {th }}$ century. The government's plan for a spatially integrated railway network continued and was accomplished by 1915 . Although the total length of the network had peaked by 1940 , there had been no major changes to the basic structure since 1915 (van der Knaap 1978), and mainly smaller local railways were realized during this period. In the 1910s, such railways were also constructed in what we call now the Groene Hart ("Green Heart," referring to a preserved and mainly rural area at the center of the Randstad); however, these were later closed as they did not flourish.

Following the growth of industry in and around bigger cities, many people moved to the cities. In the meantime, villages attempted to keep the factory workers in the village community, and railway companies helped in this respect by establishing stations on railway lines toward the city. So the easy travel opportunities provided by the railways contributed to early suburbanization. The railways also made it possible for the well-to-do to commute between their work in the city and their houses in the countryside.

During the two interwar decades, competition between the railways and road transport increased. The railways were forced to revise their services and concentrate more on longer-distance travel. Roads improved and bus services became available, sometimes as a replacement for trams, but also creating completely new links between villages and their service centers. To counter financial losses, the reduction in the number of regional railway lines led to the closure of around 150 stations (Cavallo 2007) and 100 kilometers of railways. Under such conditions, there were no more plans for the development and expansion of the railway network (Dijksterhuis 1989). This downturn is depicted clearly in Figures 2 and 3.

Railways versus motorways: 1940-1980. The era following World War II was characterized by rapid economic and demographic growth. There was a population explosion that dramatically increased the need for new housing and consequently city expansion. A shift from employment in industry to employment in business and personal services was taking place, leading to the rapid expansion of the service sector.

The road network was also improving fast. Driven by economic and population growth, a new round of industrialization and increasing prosperity, the ownership and use of private vehicles surpassed the use of the train and other means of public transport (Dijksterhuis 1989; Annema and van Wee 2009). New roads and parking places were increasingly attracting more cars onto the roads. The growing demand for the car was further supported by the government. The railway network, meanwhile, shrank in length and the number of stations fell until 1960 (see Figure 3).

During this period, urbanization continued in the form of large urban expansions in order to house population growth. From the socio-economic as well as spatial perspective, almost everything favored and promoted car ownership and use: rapid economic growth, increased distances between home and work locations, and sprawling suburbanization.

Unlike the railway, the car caused a much more diffused pattern of commuting, which led to massive suburbanization. This new type of commuting differed from previous patterns in the sense that it was no longer confined to public transport nodes (Dijksterhuis 1989). Moving away from its passive role in the 1940s and 1950s, the Dutch Railways finally became actively involved in planning during the 1960s. It shifted its policy from prioritizing connections between larger cities to linking suburbs and growth centers to the existing railway network wherever possible (Dijksterhuis 1989). Apart from the development of heavy rail, by the end of the 1960s larger cities were investing in reinforcing and developing their internal urban rail transit networks. The Rotterdam metro began operating at the end of 1960s. Amsterdam's metro and later Utrecht's fast tram followed in the 1970s and 1980s. 

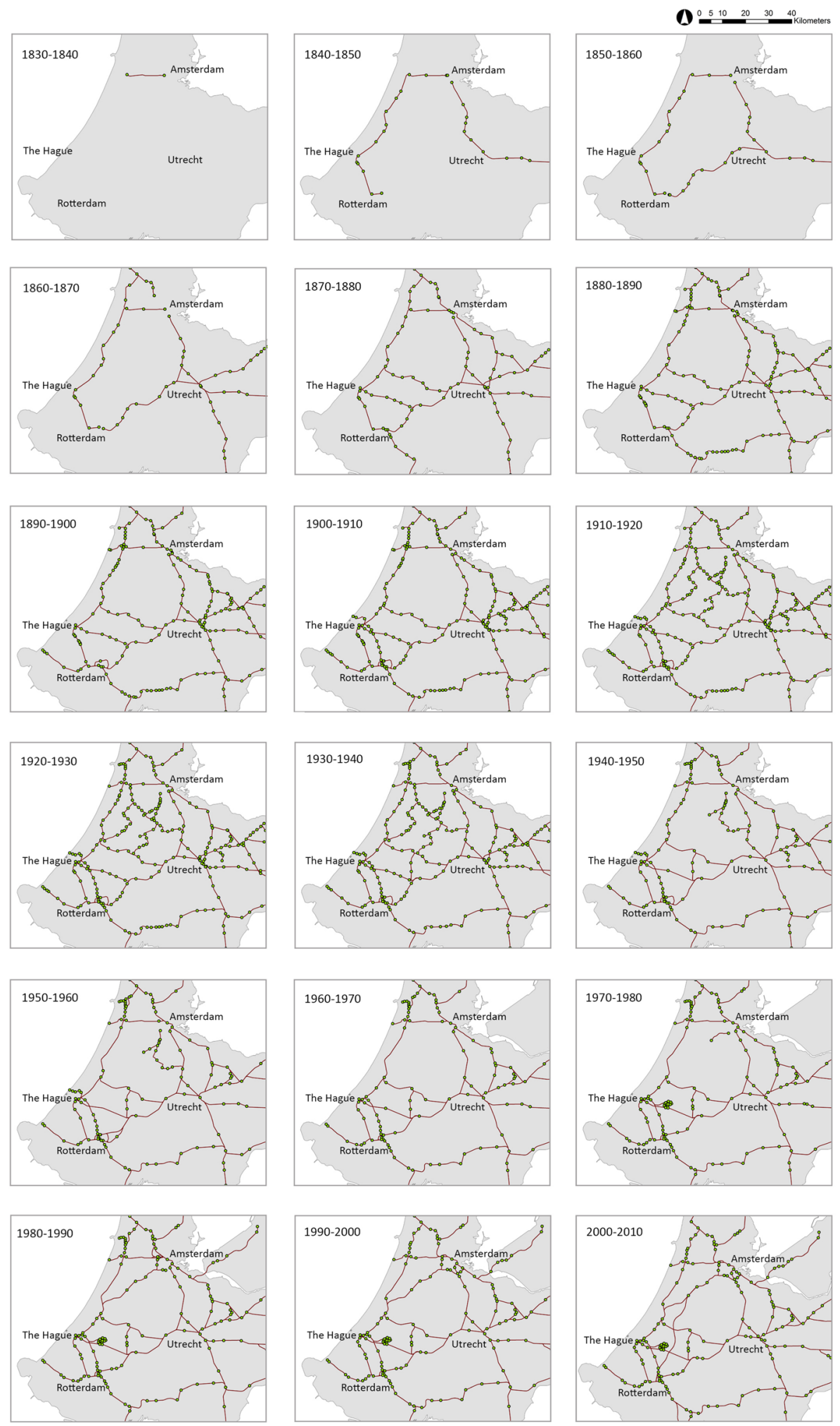

Figure 3: The development of railway lines and stations during 18 decades from 1850 to 2010. Each map shows all the railway lines and stations that existed during each decade Source: Authors 
An era of planned development: 1980-2010. The railway network continued its relatively slow growth into the 1980s. The major additions were connections with newly developed settlements and services, such as lines to connect the new town of Zoetermeer, Schiphol International Airport, and the newly reclaimed province of Flevoland. Another important addition was the decision to build a highspeed line in 1997, which was implemented in the 2000s. This was intended to improve the Netherland's international accessibility and provide a more environmentally friendly alternative to the rise in air travel (Annema and van Wee 2009).

As for BUA development, this continued with the increasing exodus to suburbs (Musterd, Jobse, and Kruythoff 1991). The population decline in central cities led to the emergence of the "compact city" policy at the end of the 1980s and during the 1990s. Previously, various planning efforts were made to curb suburbanization such as the "concentrated de-concentration" and "growth centers" policies in the 1960s and 1970s. These policies are generally assessed as having been successful in directing the growing population into certain growth centers and curbing urban sprawl (Dieleman and Wegener 2004). The Fourth Report on Physical Planning Extra (Ministry of Housing, Physical Planning and the Environment 1991), focused on channeling new urban (re)development to locations within the existing urban areas ("brownfield" locations) and new "greenfield" locations on the edges of existing cities (the so-called VINEX locations). At the same time, the Second Transport Structure Plan (Ministry of Transport, Public Works and Water Management 1990) promoted "sustainable" transport by encouraging carpooling and public transport use. It suggested the use of spatial planning and transport policy measures such as concentrating housing and employment around public transport nodes. Due to these policies, growth returned to the larger cities after a decade of severe stagnation (Geurs and van Wee 2006). In 2004, the National Spatial Strategy emphasized the concept of "network cities" which encouraged decentralization and eventually urban growth along major transport corridors. Perhaps the best example of the implementation of this concept is the Stedenbaan(Plus), an ambitious regional transit-oriented development program that combines high-frequency rail and public transport services with high-density urban developments around stations.

\section{$4 \quad$ Analysis}

In this section, we describe urbanization within different degrees of proximity to the railway stations using built-up area as an indicator. Furthermore, we test the effect of the opening of railway stations and the development of BUA in their vicinity and vice versa. Built-up area is measured at nine time points: 1850, 1910, 1940, and for each decade between 1960 and 2010, as depicted in Figure 4. Although the choice of these nine time points was primarily driven by the availability of data, the periods also coincide with some significant moments. We begin at 1850, after the opening of the first railway lines, which developed into a large railway network by the end of 1910. Observing periods of further growth and decline after 1910, we continue with 1940, which coincides approximately with the beginning of World War II. Since the 1960s, the railway network was subject to heavy competition from the motorway network, with the latter encouraging further urban sprawl. We follow the changes in the railway network and urbanization into the $21^{\text {st }}$ century when the railway network continued its post-war growth and the urbanization was channeled with the help of specific policies (1980-2010). 

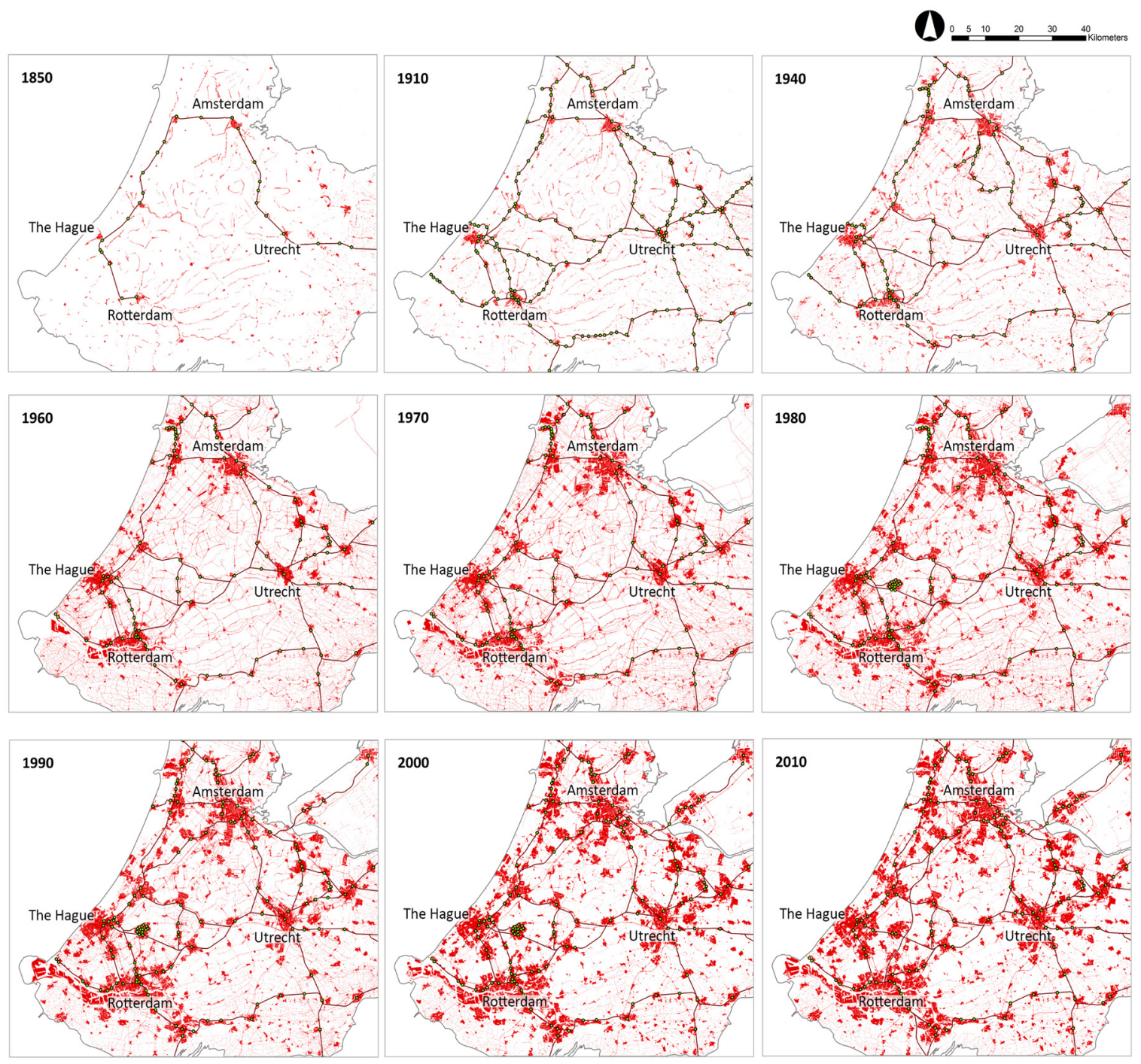

Figure 4: The development of the railway network and the built-up area between 1850 and 2010

\subsection{Effects of the railway network on the development of built-up area}

To compare the amount of built-up area (BUA) with respect to the distance to railway stations, five nonoverlapping ring-buffers with intervals of 1 kilometer were generated for existing stations at the nine points in time. Thus for years 1850, 1910, 1940, 1960, 1970, 1980, 1990, 2000, and 2010, the share of BUA within certain buffers of existing stations and for the study area as a whole were calculated. The result of these calculations is presented in Figure 5. 


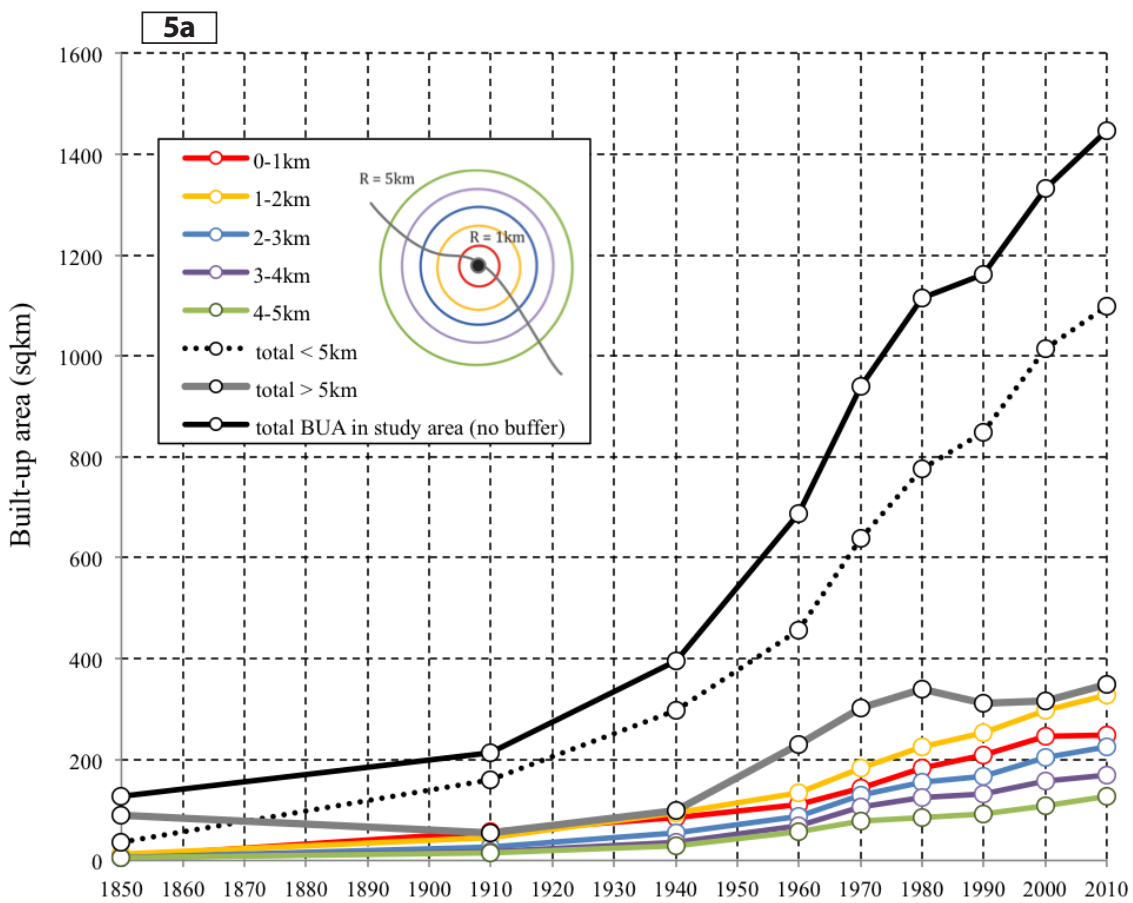

Year

\section{$5 \mathbf{b}$}

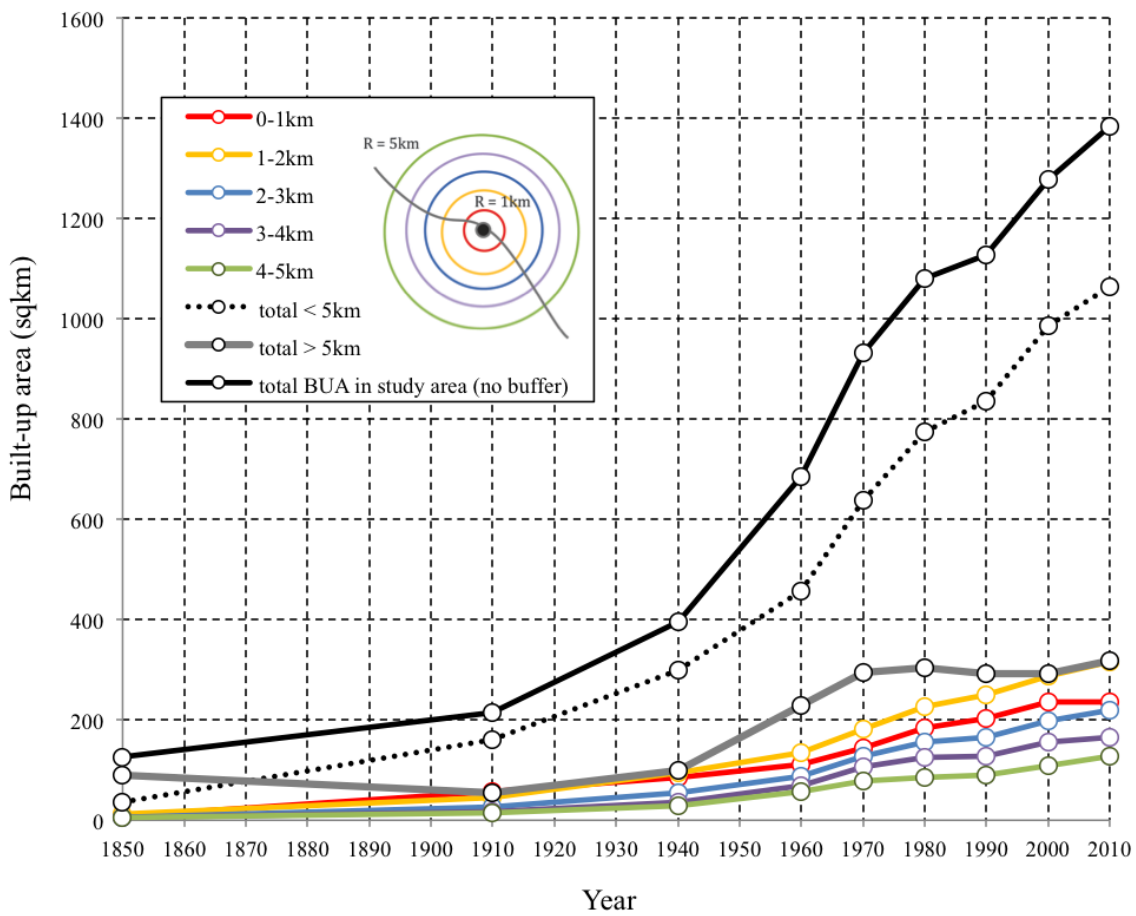

Figure 5: Development of the built-up area as a whole and within the different station buffers a) including Flevoland and b) excluding Flevoland 
As mentioned in Section 2, the borders of the Randstad study area changed during our study period. The study area has the same borders from 1850 until 1968, but it then grows by 8 percent due to the addition of the newly reclaimed Flevoland province from the IJsselmeer. We disregard relatively smaller changes such as the reclamation of the Haarlemmermeer polder at the very beginning of our study period or the gradual development of the Rotterdam harbor over the course of the $20^{\text {th }}$ century. The expansion of the study area to include Flevoland also magnified the growth of BUA. To control the growth of the study area, we also produced the same calculations without the Flevoland province. In Figure 5, we distinguish between (a) the Randstad area including Flevoland, and simply by way of comparison, (b) the area excluding Flevoland. However, general growth trends are very much the same. Since this difference is minor, and we consider the addition of Flevoland to be an important event in the growth of the Randstad, we include it in all our calculations in this paper.

Figure $5 \mathrm{a}$ shows that there is an increase in the total amount of BUA within each time period, as expected. BUA grew faster in each decade than in the previous one, until 1970 when the urbanization slowed, followed by the lowest growth rate in the 1980s. Among other factors, this may be attributed to the effectiveness of policies to curb suburbanization before the 1970s and the economic recession during the 1980s. In the last two decades, we are again observing higher increases in the amount of BUA, with smaller increases in the 2000s in comparison to the 1990s.

Until 1910, the growth of BUA within 5 kilometers of railway stations (represented as the dotted line) was slightly higher than the overall growth of BUA. This difference is possibly due to the rapid growth in the number of stations and the fact that the suburbanization was still railway-oriented at the time. After 1910, however, the growth within that zone slows compared to the overall growth in BUA. This is because of increasing development farther away from the railway stations ( $>5$ kilometers) caused by growth first in tram networks and later in car-oriented suburbanization. In the 1980s, we again observe an increase in BUA growth within 5 kilometers of stations that is higher than overall BUA growth. Unsurprisingly, urban growth in the $>5$ kilometer area experienced a fall during this period. In the 1990s, the growth of BUA continues more or less steadily overall and in the vicinity of stations $(<5$ kilometers), while in the 2000s, we witness a slight decrease in the BUA $<5$ kilometers and therefore a slight increase in the BUA > 5 kilometers.

Comparing growth in BUA in the five concentric rings, it is clear that development generally started close to the railway stations and moved outward, as development occurred less at longer distances from the stations (Figure 6). In other words, when we control for the buffer area, the first ring was always more built-up than the second and so on. This distance decay trend is accentuated by the fact that the difference between the amount of BUA in the first ring compared to the second is much larger than the second compared to the third and so forth. 


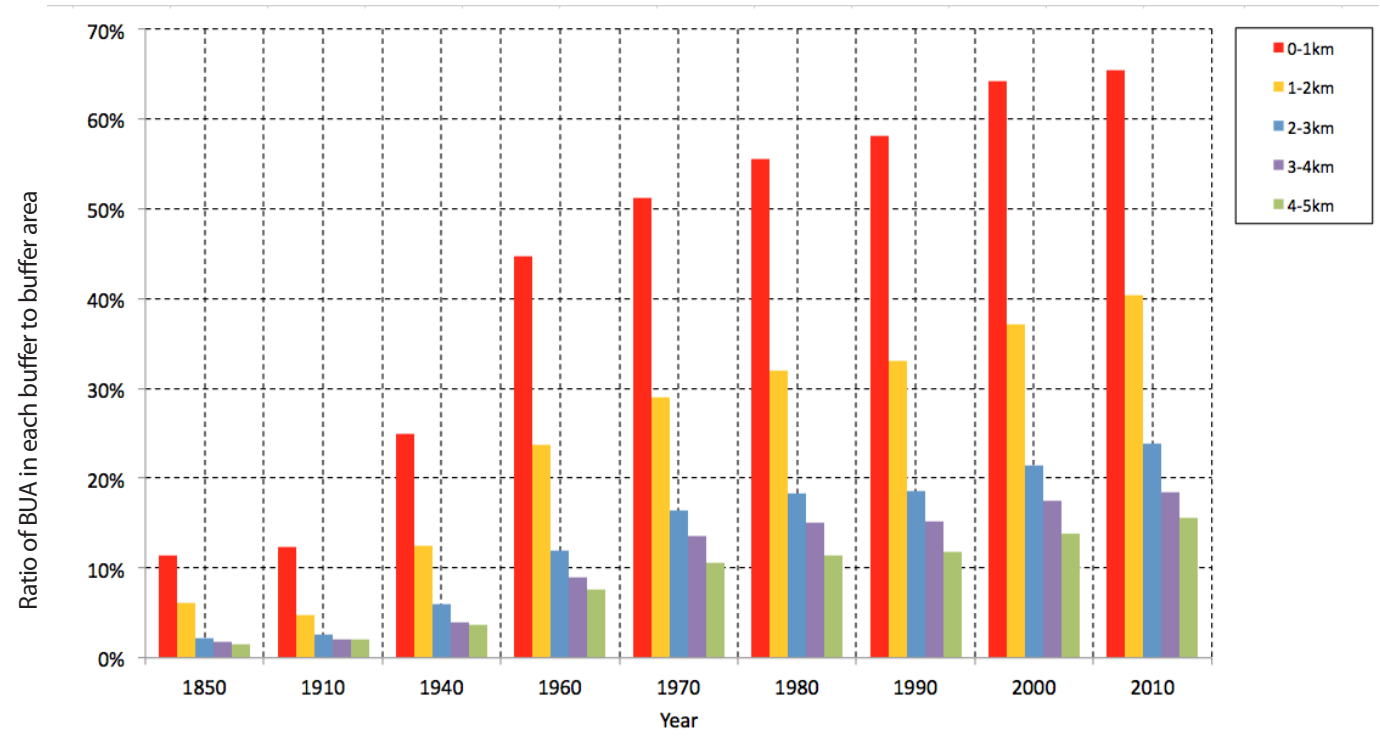

Figure 6: Ratio of BUA in each buffer to buffer area

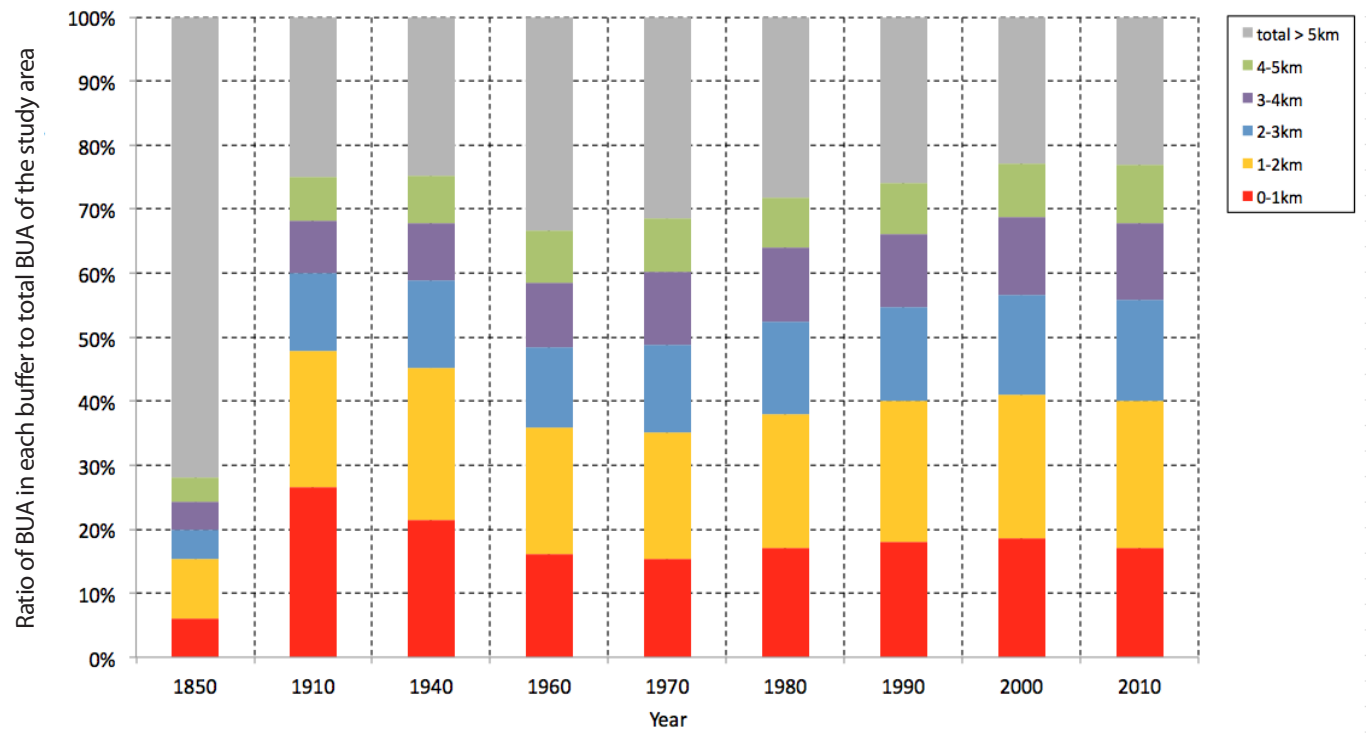

Figure 7: Ratio of BUA in each buffer to total BUA of the study area

Figure 7 presents the ratio of BUA within station buffers to the total BUA of the entire study area in each year. In other words, it shows what share of the total (100 percent) urbanization taking place in the whole study area is located within and outside the station buffers at each point in time. We can use this to compare growth in the different station buffers to overall growth in the Randstad.

Comparing the growth of BUA in the different buffers to the overall BUA of the study area, we can see that in 1850 the share of the total BUA that falls within station buffers is rather low for all rings. This is because the rail network had only just been established and the number of stations was still very limited. Later on, with the development of the rail network and the increase in number of stations, the share of BUA within station buffers increases. 
Rings three, four, and five have been fairly stable since 1910. The BUA outside the 5-kilometer buffer had a high share of the total BUA in 1850. This is because many cities did not have a railway station at this stage. In the next two periods, however, only one-fourth of the urbanized area was outside the 5-kilometer buffer. Later, by contrast, the share of BUA increases outside 5 kilometers from the railway station (34 percent, 32 percent, and 31 percent in 1960, 1970, and 1980, respectively) at the expense of the BUA within the 5-kilometer range. Here we witness the rise of suburban development. After 1980, the "old" situation was restored and the growth of BUA > 5 kilometers remained broadly stable.

\subsection{Effects of the built-up area and the opening of railway stations on each other}

In this section, we test whether the opening of railway stations encourages the development of BUA and vice versa. To do this, for each study year (the nine points in time) we measure the effect of the amount of BUA in the preceding and subsequent periods within a 5-kilometer buffer around each station, on the probability of a new station being added.

Using the qualitative and quantitative insights of the previous sections, we hypothesize that in the beginning, from 1850 until the turn of the $20^{\text {th }}$ century, stations followed the existing BUA, and so new stations were added in already urbanized areas. By contrast, during the second half of the $20^{\text {th }}$ century, new stations were not located according to existing BUA since those areas were already served by older stations; rather, the new stations were often used as a planning tool for channeling new urbanization. The existing BUA data for nine points in time results in eight periods between every two successive time points: 1850-1910, 1910-40, 1940-60, 1960-70, 1970-80, 1980-90, 1990-2000, 2000-10. We estimate seven binomial logit models, for each changeover between periods. We model the probability that a station was built in that period (1) or that it already existed (0). The independent variables are the amount of BUA in the buffer of that station in the preceding $\left(\mathrm{BUA}_{\mathrm{t}-1}\right)$ and subsequent periods $\left(\mathrm{BUA}_{\mathrm{t}+1}\right)$. For example, the cases for the 1970 model are the 5-kilometer buffers of the stations existing in 1970. The dependent variable is whether or not the station was opened in the period 1960-70 and the predictors are the amount of BUA within its buffer in 1960 and 1980. We report in terms of odds ratio, which is the likelihood of a new station being opened (compared to an existing one) for a one-unit increase in BUA. The goodness-of-fit is indicated by McFadden's pseudo $\mathrm{R}^{2}$. Note that since the full population (the entire study area) is modeled, the notion of significance is not meaningful.

Table 2: Results of seven binomial logit models for predicting the opening of new stations regarding preceding and subsequent BUA in their 5-kilometer buffers

\begin{tabular}{|c|c|c|c|c|}
\hline \multicolumn{5}{|c|}{$\begin{array}{l}\text { Dependent variable: station in } 5 \text {-kilometer buffer }(0=\text { existing, } 1=\text { opened in the preceding } \\
\text { period) }\end{array}$} \\
\hline Existing stations at & BUA $_{t-1}$ & BUA $_{t+1}$ & Pseudo $\mathbf{R}^{2}$ & No. of observations \\
\hline 1910 & 1.09 & 0.91 & 0.03 & 166 \\
\hline 1940 & 1.00 & 1.00 & 0.00 & 120 \\
\hline 1960 & 0.96 & 1.10 & 0.09 & 88 \\
\hline 1970 & 0.87 & 1.14 & 0.03 & 98 \\
\hline 1980 & 0.59 & 1.67 & 0.27 & 124 \\
\hline 1990 & 0.75 & 1.38 & 0.10 & 131 \\
\hline 2000 & 0.92 & 1.09 & 0.01 & 139 \\
\hline
\end{tabular}

As demonstrated in Table 2, for the 5-kilometer buffers of stations existing in 1910, the odds ratio for BUA in the preceding period is 1.09. An odds ratio greater than one indicates that every extra square kilometer of BUA in the preceding period (1850) increased the likelihood of a station being built between 1850 and 1910. This implies that the more urbanized an area was, the more likely it was to 
receive a new station, or in other words that the new stations followed the existing pattern of urbanization. Contrary to the preceding period, the odds ratio for the BUA in the subsequent period (1910-40) is less than one (0.91). This suggests that the BUA that existed in 1940 was less likely to be in the buffer of stations opened during 1850-1910. So the BUA developed between 1910-40 does not follow the railway stations developed earlier. We think that this result is plausible since many (almost half) of the stations existing in 1910 were closed between 1910 and 1940. Additionally, more stations (one-fifth of the stations existing in 1940) developed in the 1910-40 period, which may have encouraged the development of BUA, but this is invisible to us because we do not have matching BUA data for them during that period to include them in the model.

The model for stations existing in 1940 shows no impact for BUA in the preceding or subsequent periods. In other words, new stations, which opened during 1910 and 1940, were not influenced by the amount of BUA in their vicinity and seem not to have affected further BUA changes in their 5-kilometer buffer. This again is probably due to the fact that many stations were closed prior to 1940 and are not taken into account. We suspect that the longer interval between the earlier measuring points, which is often several decades, combined with a rapidly changing railway network (Figure 2a-e), makes it hard to predict the interaction of stations and BUA in their buffers with the current method.

The trend changes from 1940 onward. For new stations opening in the periods 1940-60, 1960$70,1970-80,1980-90$, and 1990-2000, the odds ratios for BUA in the preceding periods are less than one. This means that every extra square kilometer of BUA in the preceding period reduced the likelihood of a new station being opened in each time frame. This finding would appear logical since the more a buffer was covered by BUA, i.e., the more urbanized the area, the less space there would be for further development, so the less likely it was that a new station would be added. Hence, stations in more urbanized areas were likely to be existing stations rather than new ones. Consequently, newly added stations did not correspond to existing urbanization. In contrast to the $\mathrm{BUA}_{\mathrm{t}-1}$, the odds ratio for $\mathrm{BUA}$ in the following period $\left(\mathrm{BUA}_{\mathrm{t}+1}\right)$ is greater than one. This implies that the increase in the amount of BUA is more likely to be found around new stations. So new urban areas are likely to have developed around new stations. In short, the results show that after 1940, the new stations were more likely to open in undeveloped areas (i.e., in areas with less BUA), and they then encouraged further growth in the BUA.

We can clearly see a change in the trends of odds ratios, with pseudo- $\mathrm{R}^{2}$ suggesting that preceding and future BUAs explain most of the likelihood of stations opened during the 1970s (27 percent), followed by those opened in the 1980s (10 percent) and between 1940 and 1960 (9 percent).

\section{Conclusions}

This paper has aimed to first provide a long-term study of the development of the railway network, over the past 160 years in the Randstad and to investigate its impact on urbanization, measured as growth of built-up area, and vice versa.

We have found that the total length of railway and the total number of stations followed broadly the same trend: growing and climaxing by 1920, deteriorating between the 1930s and 1950s, stabilizing in the 1960s and resuming expansion, although at a slower pace, from the 1970s to the present day. Nevertheless, station numbers underwent more variation than total railway length. The growth of the railway network was highly associated with the growth of the built-up area. As might be expected, the railways followed the existing pattern of urbanization in the very beginning, and later urbanization developed and intensified very close to the stations. With the introduction of the car and other modes of transport, urban development farther away from stations increased, before it returned, partially, to the vicinity of stations at the turn of the $21^{\text {st }}$ century. Analyses show a distance trend whereby the rings closer to the stations (especially the 0 - to 1-kilometer buffer) are always covered by more built-up area 
than rings farther out.

We also obtained results showing a trend change in relation to the built-up area in the vicinity (5-kilometer circular buffer) of stations and in the likelihood of new stations being opened. Earlier stations, built between 1850 and 1910, followed the existing pattern of urbanization and were located in areas that were more built-up. As time went by, and in particular after World War II, new stations were

less likely to be located within established urban areas because these were already serviced by existing stations. New stations were more likely to be located in as-of-yet-undeveloped areas. Furthermore, new stations prompted urban growth, so urbanization was more likely to happen in the vicinity of the newly opened stations.

Future research will focus on modeling urbanization effects of railway stations not only in their direct vicinity but also at longer distances. This would allow us to include continuous measures of accessibility to railway stations. Adding the dynamics of the motorway network enables us to test the interaction between the rail network and the road network. Finally, in this paper, we have observed the outcome of the development of the railway network and the built-up area regardless of external factors such as planning policies. The role of transport and planning policies from the 1960s onward should be taken into account to gain a more accurate insight into the development of both the railway network and urbanization.

\section{Acknowledgements}

We would like to thank the University of Wageningen, Alterra, and the Delft University of Technology, Mapping the Randstad Holland group, for making historical land-use datasets available to us. We also thank our colleague Erik Louw for his constructive suggestions throughout the research. 


\section{References}

Alpkokin, P. 2012. Historical and critical review of spatial and transport planning in the Netherlands. Land Use Policy 29(3): 536-547.

Anas, A., R. Arnott, and K. A. Small. 1998. Urban spatial structure. Journal of Economic Literature 36(3): 1426-1464.

Annema, J. A., and B. van Wee. 2009. 200 Years of Dutch Transport Policy. Paper presented at the 15th Annual International Sustainable Development Research Conference, Utrecht, the Netherlands, July 5-8.

Atack, J., F. Bateman, M. Haines, and R. A. Margo. 2010. Did railroads induce or follow economic growth? Urbanization and population growth in the American Midwest, 1850-1860. Social Science History 34(2): 171-197.

Axhausen, K. W., P. Froelich, and M. Tschopp. 2011. Changes in Swiss accessibility since 1850. Research in Transportation Economics 31: 72-80.

Badoe, D. A., and E. J. Miller. 2000. Transportation-land-use interaction: Empirical findings in North America, and their implications for modeling. Transportation Research Part D-Transport and Environment 5(4): 235-263.

Banister, D. 2005. Unsustainable Transport: City Transport in the New Century. London: Routledge.

Banister, D., and J. Berechman. 2001. Transport investment and the promotion of economic growth. Journal of Transport Geography 9: 209-218.

Bollinger, C. R., and K. R. Ihlanfeldt. 1997. The impact of rapid rail transit on economic development: The case of Atlanta's MARTA. Journal of Urban Economics 42(2): 179-204.

Cavallo, R. 2007. Railway and the Dutch city. In OverHolland 5. Architectonische studies voor de Hollandse stad, edited by F. Claessens and H. Engel, 6-10. Amsterdam: SUN Architecture.

Centraal Bureau voor de Statistiek (CBS) and Kadaster. 2015. Mutatiereeks Bodemgebruik 1996-2010.

Clark, W. A. V., and M. Kuijpers-Linde. 1994. Commuting in restructuring urban regions. Urban Studies 31(3): 465-483.

de Jong, H. J. 1992. Les transports intérieurs aux Pays-Bas avant et pendant la formation du réseau ferroviaire (1800-1880). Histoire, Économie et Société 11(1): 61-79.

Demirel, H., E. Sertel, S. Kaya, and D. Z. Seker. 2008. Exploring impacts of road transportation on environment: A spatial approach. Desalination 226(1-3): 279-288.

Deurloo, M. C., and G. A. Hoekveld. 1980. The Population Growth of the Urban Municipalities in the Netherlands between 1849 and 1970, with Particular Reference to the period 1899-1930. Amsterdam: Free University, Institute for Geographical Studies and Urban and Regional Planning.

Dieleman, F. M., M. J. Dijst, and T. Spit. 1999. Planning the compact city: The Randstad Holland experience. European Planning Studies 7(5): 605-621.

Dieleman, F. M., and M. Wegener. 2004. Compact city and urban sprawl. Built Environment 30(4): 308-323.

Dijksterhuis, R. 1984. Spoorwegtracering en stedenbouw in Nederland; Historische analyse van een wisselwerking, de eerste eeuw: 1840-1940. Ph.D. diss. Delft, the Netherlands: Delft University of Technology.

Dijksterhuis, R. 1989. Spoorwegen en planologie. Vijftig jaar ruimtelijke ordening langs de rails. In Het Spoor; 150 Jaar Spoorwegen in Nederland, edited by J. A. Faber, 134-176. Amsterdam: Meulenhoff Informatief.

Duranton, G., and M. A. Turner. 2012. Urban growth and transportation. Review of Economic Studies 79(4): 1407-1440. 
Engel, H., and F. Claessens, eds. 2005. OverHolland 2. Architectonische studies voor de Hollandse stad. Amsterdam: Sun Architecture.

Ewing, R., and R. Cervero. 2010. Travel and the built environment. Journal of the American Planning Association 76(3): 265-294.

Geurs, K. T., and B. van Wee. 2006. Ex-post evaluation of 30 years of compact urban development in the Netherlands. Urban Studies 43(1): 139-160.

Giuliano, G. 2004. Land use impacts of transportation investments: highway and transit. In The Geography of Urban Transportation, edited by S. Hanson and G. Giuliano, 237-273. New York: The Guilford Press.

Giuliano, G., C. Redfearn, A. Agarwal, and S. He. 2012. Network accessibility and employment centers. Urban Studies 49(1): 77-95.

Herranz-Loncán, A. 2007. The spatial distribution of Spanish transport infrastructure between 1860 and 1930. Annals of Regional Science 41(1): 189-208.

Hoyt, H. 1939. The structure and growth of residential neighborhoods in American cities. Washington, DC: US Government Printing Office.

Huang, W. 1994. The effects of transportation infrastructure on nearby property values: A review of literature. Working Paper 620: Berkeley, CA: Institute of Urban and Regional Development, University of California Berkeley.

Koopmans, C., P. Rietveld, and A. Huijg. 2012. An accessibility approach to railways and municipal population growth, 1840-1930. Journal of Transport Geography 25: 98-104.

Kramer, H., and G. van Dorland. 2009. Historisch Brondgebruik Nederland: een Landelijke Reconstructie van het Grondgebruik Rond 1990. Wageningen, the Netherlands: Alterra, Wageningen University.

Laan, L. van der, 1998. Changing urban systems: An empirical analysis at two spatial levels. Regional Studies 32(3): 235-247.

Ministry of Housing, Physical Planning and the Environment. 1991. Fourth Report on Physical Planning (Extra). The Hague.

Ministry of Transport, Public Works and Water Management. 1990. Second Transport Structure Plan, Part D: Government Decision. The Hague.

Mumford, L. 1961. The city in history: Its origins, its transformations, and its prospects. In The History of the City, edited by L. Benevolo. New York: Harcourt, Brace and World.

Musterd, S., R. B. Jobse, and H. M. Kruythoff. 1991. Residential mobility and urban change in the Randstad: Some (dis)similarities between Amsterdam, Rotterdam and The Hague. Housing and the Built Environment 6(2): 101-113.

Nationaal Georegister. 2011. Nationaal Wegen Bestand Spoorwegen WMS.

Rietveld, P., and F. Bruinsma. 1998. Is Transport Infrastructure Effective? Berlin: Springer.

Rodrigue, J. P., C. Comtois, and B. Slack. 2009. The Geography of Transport Systems. New York: Routledge.

Schmal, H. 2003. Cities and railways in the Netherlands between 1830 and 1860. In The City and the Railway in Europe, edited by R. Roth and M. N. Polino, 29-44. Surrey, UK: Ashgate Publishing Limited.

Sluiter, J. W. 2002. Overzicht van de Nederlandse Spoor en Tramweg-Bedrijven. Utrecht, the Netherlands: Matrijs.

Stanilov, K. 2003. Accessibility and land use: The case of suburban Seattle, 1960-1990. Regional Studies 37(8): 783-794.

van der Knaap, G. A. 1978. A spatial analysis of the evolution of an urban system: The case of the Netherlands. Ph.D. diss. Rotterdam: Erasmus University. 
van Eck, J. R., and D. Snellen. 2006. Is the Randstad a city network? Evidence from commuting patterns. Presented at the European Transport Conference, September 18, Strasbourg.

Wegener, M., F. Gnad, and M. Vannahme. 1986. The time scale of urban change. In Advances in Urban Systems Modeling, edited by B. Hutchinson and M. Batty, 175-197. Amsterdam: North-Holland Publishing. 